\title{
Treatment of plantar ulcers in leprosy patients in the community with adhesive zinc tape
}

\author{
R T WALTON,* E P FRITSCHI \& V A UMAPATHY \\ Schieffelin Leprosy Research and Training Centre, Karigiri, North \\ Arcot District, Tamil Nadu, Pin 632 106, India
}

Accepted for publication 10 July 1985

Summary The prevalence of plantar ulcers in 1483 leprosy patients attending village clinics in South India was $4.3 \%$. Patients with 'simple' ulcers, i.e. involving only skin and subcutaneous tissue containing no necrotic bone or fibrous tissue and not obviously infected, were randomly allocated to treatment with zinc oxide impregnated adhesive plaster (zinc tape) or conventional antiseptic soaked gauze dressings. The 2 groups were comparable in age, sex, type of leprosy, the length of time the ulcer had been present and the distance walked each day.

The area of the ulcer was estimated before treatment and after one month. Four ulcers treated with zinc tape healed completely compared with 2 in the control group and mean ulcer area fell from $91.9 \pm 11.3 \mathrm{~mm}^{2}$ (mean \pm SEM) to $42 \cdot 4 \pm 15.5 \mathrm{~mm}^{2}$ in the zinc tape group, and from $89 \cdot 8 \pm 13.9 \mathrm{~mm}^{2}$ to $56 \cdot 7 \pm 17 \cdot 4$ $\mathrm{mm}^{2}$ in the control group.

It is concluded that zinc tape is at least as effective as ordinary dressings in healing ulcers. It is more acceptable to patients than untidy, dirty bandages and so deserves more widespread use.

\section{Introduction}

Neuropathic foot ulcers are a significant cause of morbidity in patients suffering from leprosy, and the correct treatment of the ulcers is an important part of patient care. The ulcers arise as a result of loss of sensation over the skin of the foot.

In patients with normal gait, weight is transferred first from the heel then along the lateral border of the foot to the 5th metatarsal, from there across the metatarsal heads to the first metatarsal and thence to the pad of the great toe. Ulcers invariably lie along this line, most occurring over the 1st and 2nd metatarsal heads, and to a lesser extent the heels and part of the great toe. ${ }^{1}$

Ulcers are usually debrided if necessary and treated with antiseptics then

* St George's Hospital, Blackshaw Road, London, SW17, England. 
covered with thick gauze pads, and the foot extensively bandaged. Ulcers less than $2 \mathrm{~cm}$ in diameter treated in this way will heal in approximately 30 days $^{2}$ under hospital supervision. The white bandages are unsightly and quickly become filthy. The antiseptic soaks through staining the bandages yellow and inevitably with continued use they become ragged and malodourous.

The use of below-knee (BK) plaster of Paris results in rapid healing (3-4 weeks) and has been used for many years ${ }^{3}$ although these are again unsightly, inconvenient and generally disliked by patients. More recently the smaller, cheaper plaster shoe has proved an effective alternative to the BK plaster ${ }^{4,5}$ and since the ankle is not immobilized may cause less problems with disuse osteoporosis. Plaster shoes are also more acceptable to patients. Once healed the recurrence of the ulcer may be prevented by regular foot care and the wearing of footwear with microcellular rubber soles. ${ }^{6}$

Direct application of zinc oxide impregnated adhesive plaster (zinc tape) first suggested by Dr Stenstrom in 1976 has proved successful in healing ulcers in hospital patients and may heal them more quickly than gauze dressings. ${ }^{2}$ The tape acts as an occlusive dressing and small amounts of zinc diffuse into the granulation tissue raising serum zinc levels. ${ }^{7}$ Zinc deficiency is common in leprosy patients, ${ }^{8}$ and leads to slow healing. Zinc supplements are advocated for zinc deficient patients with leg ulcers, ${ }^{9}$ and local application seems a convenient way of raising tissue concentrations while avoiding systemic side effects. The tape has the advantage over bandages of being undetectable to the casual observer.

The results of a randomized controlled trial of zinc tape in the treatment of plantar ulcers under field conditions are presented.

\section{Patients and methods}

Patients were selected from those attending peripatetic village clinics, based around the Schieffelin Leprosy Research and Training Centre, Karigiri, South India. The area is predominantly rural, patients spending many hours of the day working in the fields and sugar plantations.

Each village in the area is visited once a month by the clinic. All patients attending the clinics in a two-week period were screened for plantar ulcers and from these those with 'simple' plantar ulcers were selected. Simple ulcers were defined as those involving only skin and subcutaneous tissue, not infected, and containing no necrotic bone or fibrous tissue. Consecutive cases were randomly allocated to zinc tape or control groups. All ulcers in the study were cleaned with an antiseptic solution of cetrimide followed by ethanol which ensures thorough drying, necessary for adhesion of the plaster. Routine debridement of the edges was carried out, and the ulcers probed if necessary, to ensure that there were no deep sinuses.

Ulcers in the control group were dressed with gauze soaked in MGSA (a paste of magnesium sulphate and glycerin with proflavin and benzalkonium choride). 
The foot was bandaged with plain linen bandages. To the ulcers in the zinc tape group $2 \mathrm{~cm}$ wide strips were applied covering the ulcer and approximately $2 \mathrm{~cm}$ of healthy skin around it.

In each case the patient was supplied with sufficient materials to change the dressing once, before the clinic was visited again the next month. Each patient was supplied with sandals made with micro-cellular rubber soles, with an individually tailored arch support. The size of the ulcer was measured before and after one month of treatment. The response was assessed by a change in area.

Demographic data were collected together with information about the wearing of shoes, duration and position of the ulcer, the type of leprosy (lepromatous or non-lepromatous) and the estimated distance walked each day.

\section{Results}

Of the 2328 patients due to attend 12 clinics in the two-week study period for routine prescription of drugs and assessment of response to treatment, 1483 $(63 \%)$ actually attended: of these, $63(4.3 \%)$ had plantar ulcers and 43 of these fulfilled the criteria for simple plantar ulcers.

The distribution of the ulcers over the foot (Table 1) was in accordance with that found by other workers, ${ }^{2}$ being predominantly over the 1 st and 2 nd metatarsal heads. One patient developed an ulcer over the cuboid bone. Some patients were seen with ulcers over the lateral malleolus caused by sitting crosslegged. These were not entered into the study.

Random allocation resulted in 22 ulcers in the new treatment group and 21 in the control group. Fourteen patients from each group returned to the clinic after one month $(65 \%)$.

Four ulcers treated with zinc tape healed completely compared to 2 in the control group. The mean ulcer area in the control group was $89.9 \pm 13.9 \mathrm{~mm}^{2}$ (mean \pm SEM) this fell to $56 \cdot 7 \pm 17 \cdot 4 \mathrm{~mm}^{2}$ after one month of treatment. In the zinc tape group the mean ulcer area fell from $91.9 \pm 11.3 \mathrm{~mm}^{2}$ to $42.4 \pm 15.5 \mathrm{~mm}^{2}$ after one month.

Table 1

\begin{tabular}{lc}
\hline \multicolumn{1}{c}{ Site of ulcer } & $\begin{array}{c}\text { Number of ulcers } \\
\text { found at that site }\end{array}$ \\
\hline Pad of great toe & 4 \\
1st metatarsal head & 8 \\
2nd metatarsal head & 6 \\
3rd metatarsal head & 2 \\
4th metatarsal head & 2 \\
5th metatarsal head & 3 \\
Cuboid & 1 \\
Calcaneum & 2 \\
\hline
\end{tabular}


The difference between the means is $14.3 \mathrm{~mm}^{2}$. Because of the wide variance of the sample the difference in favour of zinc tape is not significant (Students $t=$ test: $t=0 \cdot 83 P=0 \cdot 4)$.

The 2 groups were comparable in terms of distance walked each day, duration of the ulcer, sex and classification of leprosy. The zinc tape group was rather younger (mean $41.9 \pm 16.8$ years) than the control group (mean $50 \pm 8.2$ years) but this difference is not significant $(t=1 \cdot 63 P=0 \cdot 2)$.

\section{Discussion}

The results show a prevalence of plantar ulcers among leprosy patients of $4.3 \%$, which indicates the magnitude of the problem. Even if the disease is successfully treated, nerve damage may be permanent in many cases. A simple, quick and cheap method of treating plantar ulcers is needed; zinc oxide adhesive tape may well fulfil these criteria. It has the advantage over bandaging in that it is invisible with the patient's foot inside the sandal, and is therefore less stigmatizing. Zinc tape may also be more effective than conventional dressing, although the advantage shown in this small study did not reach statistical significance.

\section{Acknowledgments}

I thank Dr R Anderson and Dr D Banerjee for their help and advice; and Dr M Bland for his advice on statistical treatment. R $\mathrm{T}$ Walton was supported by a grant from the Medical Research Council.

\section{References}

${ }^{1}$ Belsare RK, Prasada Raju BLN, Bami S. India Journal of Surgery, 1979; 41: No 6, 341-6.

2 Soderberg T, Hallmans G, Stenstrom S, Lobo D, Pinto J, Maroof S, Vellut C. Treatment of leprosy wounds with adhesive zinc tape. Lepr Rev, 1982; 53: 271-6.

${ }^{3}$ Khan JJ. The treatment of trophic ulcers. Lepr India, 1939; 11: 19-21.

${ }^{4}$ Pring DJ, Casiebanca N. Simple plantar ulcers treated by below knee plaster and moulded double rocker plaster shoe-a comparative study. Lepr Rev, 1982; 53: 261-4.

5 Joseph B, Joshua S, Fritschi EP. The moulded double rocker plaster shoe in the treatment of plantar ulcer. Lepr Rev, 1983; 54: 39-44.

${ }^{6}$ Bauman JH, Girling JP, Brand PW. Plantar pressures and trophic ulceration: an evaluation of footwear. J Bone Jt Surg, 1963; 45B: 653-7.

${ }^{7}$ Hallmans G. Absorption of topically applied zinc and changes in zinc metabolism during wound healing. Acta Dermato Venerol, 1978; 58: suppl 80.

8 Oon BB, Khong KV, Greaves MW, Plummer UM. Trophic skin ulceration in leprosy. Br Med J, 1974; 2: 531.

9 Wiseman K. Zinc metabolism and the skin. In: Recent Advances in Dermatology 5. Rook A, Sarin JA (eds) pp 109-29. Churchill Livingstone, Edinburgh. 1980. 